\title{
Expanding the scope of EJNMMI in the era of electronic publishing
}

\author{
Ignasi Carrió
}

Published online: 2 November 2010

(C) Springer-Verlag 2010

Dear readers,

The European Journal of Nuclear Medicine and Molecular Imaging (EJNMMI) has continued to progress in 2010. Over the year we have published: 24 Editorials, 189 Original Articles, 12 Review Articles, 15 Images of the Month, 15 Letters to the Editor, 12 Guidelines and 11 Focus On... articles. As angiogenesis is one of the hallmarks of cancer and is increasingly in the focus of oncological research, a comprehensive supplement on Imaging of Angiogenesis, edited by Dr. Ambros Beer and Dr. Xiaoyuan Chen, was published in August this year [1]. In all issues of the journal, invited editorial commentaries written by expert leaders have put special papers into appropriate perspective.

Original Articles have presented the best clinical and basic research performed in the field of nuclear medicine and molecular imaging. These articles were selected from more than 1,000 submissions coming from all over the world, which reflects the increasing global scope of EJNMMI. The Review Articles, edited by Prof. Angelika Bischof Delaloye, have addressed relevant and timely topics in the field, offering balanced and updated reviews. Prof. Luc Mortelmans has selected the Images of the Month that could bring the most demonstrative information in just one picture or panel accompanied by a short description and a few references. This year, a significant number of Guidelines have been published. These documents have presented the work of the EANM committees and expert bodies and have recommended appropriate procedures and defined best practice. Because Guidelines are counted as Original Articles for calculation of the impact factor, the number published in the future will be adjusted to keep up

I. Carrió $(\bowtie)$

Barcelona, Spain

e-mail: icarrio@santpau.es with the journal's needs in this regard. The Focus On... section, as edited by Prof. Giovanni Lucignani, has continued to compile the most recent information from the current medical literature on interesting and hot topics. Once again, the Editorial Office, Associate Editors and Editorial Board have been committed to present our readers the year's best contributions to the vibrant field of nuclear medicine and molecular imaging.

The number of articles submitted to EJNMMI continues to grow, with more than 1,100 submissions per annum. As space in the journal is limited, the acceptance rate in EJNMMI is now $19 \%$ for Original Articles. The editorial decision comes after thoughtful and detailed peer review, including evaluation of the relevance and priority of the subject of the manuscript. Sometimes, with the sole intention of speeding up the process and saving time for authors and reviewers, an immediate decision to decline a paper is taken at the Editorial Office, in particular when the subject of the article is beyond the scope of the journal or the paper is judged by the editors to be more appropriate for another journal. As in previous years, I wish to express my recognition to the expert peers who have participated in the EJNMMI review process, in particular those who do not belong to the Editorial Board. More than 1,300 experts from all over the world have participated in the 2010 EJNMMI review process. In the name of the Editorial Board, authors and readers, my sincere gratitude goes to them all.

The journal's performance can be illustrated by the following figures. The average time from submission to first decision in 2010 has been 24 days; the average time from submission to final acceptance has been 64 days (including revision, re-submission and re-evaluation), and that from submission to rejection has been 24 days. The selection of reviewers is made from the EJNMMI expert 
database, which contains hundreds of names derived from a continuous search of the literature based upon relevant keywords. Therefore, authors should carefully select the keywords that most accurately reflect their work in order to facilitate the selection of the most appropriate reviewers. EJNMMI indices in 2010 continue to indicate that the journal is advancing. The 2009 impact factor remains steady at 4.531 despite the higher number of articles published (2,057 citations of 454 articles). Our immediacy index (citations of articles published in the same year) is 0.849 , reflecting high visibility and easy online access to EJNMMI, and helps citation of our articles within the time window of 2 years required for the impact factor calculation [2]. The cited half-life (number of publication years from the current year which account for $50 \%$ of current citations) is 5.9 years, and the total number of citations in 2009 increased to 8,825 (source: Thompson Institute for Scientific Information's Journal Citation Reports).

The EJNMMI has again given its annual awards to acknowledge excellence in clinical and basic research published in the journal. The 2010 awards were presented at the closing ceremony of the EANM 2010 congress in Vienna. An article reporting the first clinicopathological series of longitudinal FDG-PET scans in cognitively normal elderly people followed to the onset of post-mortem verified Alzheimer's disease, by Lisa Mosconi et al. [3] from New York, was adjudged the best clinical paper in 2009. The article demonstrates that progressive reductions in glucose metabolic rate occur years in advance of clinical symptoms in patients with verified Alzheimer's disease. The award for best basic science paper in 2009 went to an article on radiolabeled cyclic RGD peptides with potential for early tumour detection and non-invasive monitoring of tumour metastasis and therapeutic response. This paper, by Zhaofei Liu et al. [4] from Stanford, reports on two novel RGD dimers with high affinity, high specificity and good pharmacokinetic properties for clinical PET imaging of integrins in cancer patients. The most cited EJNMMI paper for 2009 (among articles published in 2006 and cited between 2006 and 2009) was an article from Aviano in Italy evaluating the potential of PET-CT and fluoromethylcholine in the assessment of suspected recurrence of prostate cancer after treatment. This article, by Mario Cimitan et al. [5], shows that fluoromethylcholine PET-CT has a significant impact on the management of prostate cancer patients with biochemical recurrence and PSA values over $4 \mathrm{ng} / \mathrm{ml}$. PET-CT can exclude distant metastases in selected patients with intended local salvage treatment.
The most important development this year maybe the launching of an EJNMMI companion journal, EJNMMI Research. This is a new, independent, peer reviewed, online-only journal. While EJNMMI remains a widely read and highly cited nuclear medicine journal with an international reputation for excellence, the new companion journal brings an additional opportunity for authors to publish their work. In the era of electronic publishing, other major medical journals have acted similarly, taking advantage of the powerful brand name based on the initials of an established and highly influential journal and founding one or more related journals to expand the publishing opportunities in a given field. The appointed Editor-inChief of EJNMMI Research, Prof. Bischof Delaloye, will address the aims and scope of this new journal in detail in a special Editorial to be published in the January 2011 issue of EJNMMI.

At the end of the year, my personal note of thanks always goes to those people who dedicate their time and professional expertise to the success of the journal: Carmina Jimenez, my editorial assistant, who ensures appropriate handling of the manuscripts in the system; David Roseveare, who is responsible for the efficient production process; Claudia Schiffers, who takes care of the journal's website and online system; and Sabine Ben Ghechir, who coordinates the office at Springer. Dear colleagues and readers, I hope that the European Journal of Nuclear Medicine and Molecular Imaging will continue advancing next year, and wish you all a very successful 2011!

Ignasi Carrió

Editor-in-Chief, EJNMMI

\section{References}

1. Beer AJ, Chen X. Imaging of angiogenesis: from morphology to molecules and from bench to bedside. Eur J Nucl Med Mol Imaging. 2010;37 Supp1 1:S1-3.

2. Carrió I. Of impact, metrics and ethics. Eur J Nucl Med Mol Imaging. 2008;35:1049-50.

3. Mosconi L, Mistu R, Switalsky R, et al. FDG-PET changes in glucose metabolism from normal cognition to pathologically verified Alzheimer's disease. Eur J Nucl Med Mol Imaging. 2009;36:811-22.

4. Liu Z, Niu G, Shi J, et al. 68-Ga labelled RGD dimers with Gly3 and PE G4 linkers: promising agents for integrin imaging. Eur J Nucl Med Mol Imaging. 2009;36:947-57.

5. Cimitan M, Bortolus R, Morassut S, et al. 18F-Fluorocholine PET/CT imaging for the detection of recurrent prostate cancer at PSA relapse: experience in 100 consecutive patients. Eur J Nucl Med Mol Imaging. 2006;33:1387-98. 